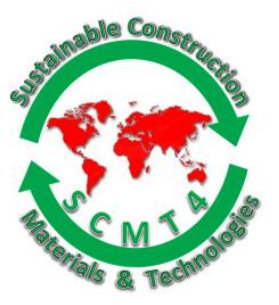

SCMT4

Las Vegas, USA, August 7-11, 2016

\title{
Effect of Test Parameters on Behavior of Circular GFRP Reinforced Concrete Columns
}

\author{
Hamdy M. Mohamed ${ }^{1}$ \\ ${ }^{I}$ Department of Civil Engineering; Helwan University - Cairo, Egypt. Assistant Professor \\ Email:<Dr.HamdyMohamed@Gmail.com>.
}

\begin{abstract}
Meanwhile, the behavior of concrete members reinforced with fiber-reinforced-polymer (FRP) bars has been the focus of many studies in recent years. However, limited research work has been conducted to examine the axial behavior of concrete columns reinforced with FRP bars. This paper reports on twelve full-scale circular reinforced-concrete (RC) columns were tested under concentric axial load. The columns were reinforced with longitudinal glass-FRP (GFRP) bars and newly developed GFRP spirals. The $300 \mathrm{~mm}$ diameter columns were designed according to CAN/CSA S806-12 code requirements. The test parameters included reinforcement type (GFRP versus steel); longitudinal FRP reinforcement ratio; and the volumetric ratios, diameters, and spacing of spiral reinforcement. The test results indicated that the GFRP and steel RC columns behaved in a similar manner. The average load carried by the longitudinal GFRP bars ranged between 5\% and $10 \%$ of the maximum load. The ductility and confinement efficiency can be better improved by using small GFRP spirals with closer spacing rather than larger diameters with greater spacing.
\end{abstract}

\section{INTRODUCTION}

Recent years have seen valuable research work on and widespread applications of fiber-reinforced-polymer (FRP) bars as flexural and shear reinforcement for concrete structures (ISIS Canada 2009). Nonetheless, the axial behavior of FRP RC compression members has not yet been defined. ACI 440.1R-06 highlights that further research is needed in this area. Testing of FRP bars in compression is typically complicated by the occurrence of fiber micro-buckling due to the anisotropic and nonhomogeneous nature of the FRP material. Therefore, a standard test method for FRP bars under compressive axial loading has not yet been introduced. On the other hand, ACI 440.1R-06 does not recommend the use of FRP bars as longitudinal reinforcement in columns. Moreover, Canadian codes (CSA S6-06 and CSA S806-12) neglect the contribution of the compressive resistance of FRP longitudinal reinforcement in the compression zone in flexural and compressive concrete members.

While FRP bars have many favorable characteristics for use as flexural tension reinforcement, some fundamental properties need to be defined for use in compression members. Previous research indicates that the strength and modulus of FRP bars in compression are lower than that in tension. Kobayashi and Fujisaki (1995) tested small-scale square FRP RC columns (200 x 200 x $650 \mathrm{~mm}$ ). The specimens were 
reinforced longitudinally by grid type FRP. It was concluded that the axial capacity of FRP RC columns could be estimated conservatively by ignoring the contribution of FRP bars. Sharma et al. (2005) reported on the axial load capacities of square concrete columns reinforced with GFRP bars with three different reinforcement ratios: $0.723,1.08$, and $1.45 \%$. Their study indicated that increasing the reinforcement ratio increased the ductility. Luca et al. (2010) carried out tests on five full-scale RC square column specimens reinforced with GFRP bars and ties. They reported that the behavior of GFRP RC columns was similar to that reinforced with steel bars. Their results also indicated that the contribution of the GFRP and steel bars as internal reinforcement to the column capacity, however, was about $5 \%$ and $12 \%$, respectively, of the peak load. Lotfy (2010) tested square concrete columns (with three different reinforcement ratios of GFRP bars). The study reported that increasing the reinforcement ratio increased column ductility. A recent study reported on by Tobbi et al. (2012) assessed the compression behavior of square RC columns reinforced with FRP bars and ties. According to its findings, column nominal capacity can be calculated considering the compressive strength of GFRP bars to be equal to $35 \%$ of its tensile strength. In conclusion, the aforementioned research works indicated that the compression behavior of FRP reinforcement has been subjected to significant variation and that test data were scattered. There is a consensus that FRP bars have lower compression strength than tensile strength, whereas the strength of GFRP bars in compression varied from $30 \%$ to $77 \%$ in tension. So far, however, only a few studies have investigated the behavior of concrete columns reinforced with FRP bars and ties or spirals. This paper reports the test results of concentrically tested circular concrete columns reinforced with GFRP bars and spirals.

\section{EXPERIMENTAL INVESTIGATION}

\section{Materials}

Sand-coated GFRP bars and GFRP spirals were used to reinforce the GFRP RC column specimens (see Figure 1) (Pultrall 2012). The GFRP bars and spirals were made of continuous E-glass fibers impregnated in a thermosetting vinyl-ester resin. No. $15.9 \mathrm{~mm}$ GFRP bars were used as longitudinal reinforcement. No. $6.4 \mathrm{~mm}$, No. $9.5 \mathrm{~mm}$, and No. $12.7 \mathrm{~mm}$ GFRP spiral reinforcements were used as spiral reinforcement. Deformed steel bars M15 were used as longitudinal reinforcement, while, mild steel bars M10 served as transverse spiral reinforcement. Table 1 provided the properties of GFRP and steel bars. All column specimens were cast on the same day with normal-weight, ready-mixed concrete with an average compressive strength of $42.9 \mathrm{MPa}$.

Table 1. Tensile properties of the GFRP and steel bars

\begin{tabular}{|c|c|c|c|c|c|}
\hline $\begin{array}{c}\text { Bar } \\
\text { Size }\end{array}$ & $\begin{array}{c}\text { Diameter } \\
(\mathrm{mm})\end{array}$ & $\begin{array}{c}\text { Area } \\
\left(\mathrm{mm}^{2}\right)\end{array}$ & $\begin{array}{c}\text { Elastic Tensile Modulus } \\
(\mathrm{GPa})\end{array}$ & $\begin{array}{c}\text { Tensile Strength } \\
(\mathrm{MPa})\end{array}$ & $\begin{array}{c}\text { Tensile Strain } \\
(\%)\end{array}$ \\
\hline \multicolumn{7}{|c|}{\begin{tabular}{c} 
GFRP bars \\
\multicolumn{7}{|c|}{}
\end{tabular}} & \\
\hline$\# 2$ & 6.4 & 32 & 52.5 & $f_{f u}=938$ & 1.90 \\
\hline$\# 3$ & 9.5 & 71 & 53.4 & $f_{f u}=889$ & 1.89 \\
\hline$\# 4$ & 12.7 & 129 & 53.6 & $f_{f u}=941$ & 1.70 \\
\hline$\# 5$ & 15.9 & 199 & 55.4 & & 1.56 \\
\hline \multicolumn{7}{|c|}{ Steel bars } & $f_{y}=460$ & 0.2 \\
\hline M10 & 9.5 & 71 & 200 & $f_{y}=460$ & 0.2 \\
\hline M15 & 16 & 200 & 200 & & \\
\hline
\end{tabular}




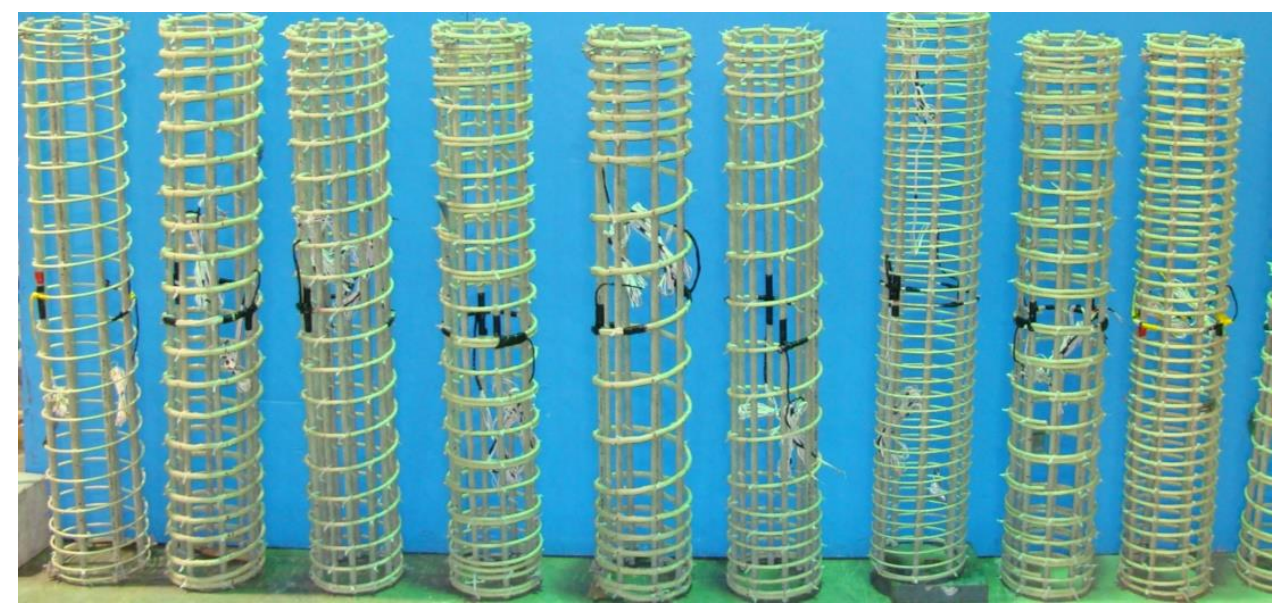

Figure 1. Overview of GFRP cages with different configurations

\section{Specimen details}

In this study, full-scale circular RC columns were prepared and tested under monotonically increasing pure axial load. They included 9 RC columns reinforced with longitudinal GFRP bars and traverse GFRP spirals. The remaining 3 columns were prepared as references: one plain-concrete and two steel RC columns. All tested specimens measured $300 \mathrm{~mm}$ in diameter and $1500 \mathrm{~mm}$ in height. The test matrix was arranged to assess the influence of reinforcement type (GFRP versus steel); longitudinal FRP-reinforcement ratio; and different volumetric ratios, diameters, and spacing of spiral reinforcement. Table 2 provides the test matrix and reinforcement details of the column specimens. The specimens were divided into five groups according to test matrix. Group I includes three control specimens: plain-concrete column (P) without reinforcement and two steel RC specimens (S1 and S2). The two steel specimens were reinforced longitudinally with 6 M15 steel bars and transversely with M10 steel spirals with pitches of 80 and $40 \mathrm{~mm}$. These control specimens were introduced into the experimental program as references for comparison with GFRP RC columns. Group II includes three specimens to study the effect of GFRP longitudinal reinforcement ratio (G2, G1, and G3). The two GFRP RC columns (G6 and G1) were designed to have 8 longitudinal M15 steel bars based on the equivalent strength of 6 longitudinal steel bars used in the two counterpart specimens (S1 and $\mathrm{S} 2$ ).

Group III, IV, and V specimens served to study the effect of lateral reinforcement parameters on axial capacity in terms of volumetric ratios, diameters, and spacing of spiral reinforcement. The specimens in these groups were reinforced longitudinally with 8 No. $15.9 \mathrm{~mm}$ GFRP bars. Specimen G1 served as a reference for the three groups. The influence of spiral diameter (size) was considered in Group III by using No. $6.4 \mathrm{~mm}$, No. $9.5 \mathrm{~mm}$, and No. $12.7 \mathrm{~mm}$ GFRP spirals with a constant pitch of $80 \mathrm{~mm}$ in specimens G4, G1, and G5, respectively. Group IV included three specimens (G6, G6, and G7) to study the effect of spiral spacing with three different spacings of No. $9.5 \mathrm{~mm}$ spirals $(40,80$, and $120 \mathrm{~mm}$ ), respectively. Finally, Group V included three specimens (G8, G1, and G9) to study the effect of spiral size / spacing configuration, while maintaining a constant volumetric ratio $\left(\rho_{\mathrm{st}}=1.5\right)$. Three spiral diameters $($ No. $6.4 \mathrm{~mm}$, No. $9.5 \mathrm{~mm}$, and No. $12.7 \mathrm{~mm}$ ) were used with three different spacings $(35,80$, and $145 \mathrm{~mm}$ ), respectively, in preparing columns in Group V. The longitudinal steel or GFRP bars were instrumented with electrical strain gauges at mid-length. Four linear variable differential transducers (LVDTs) were located in the test region to measure the axial deformations of each specimen. Finally, the column specimens were tested under pure axial compression load using an 11,400 kN MTS testing machine (see Figure 2). 


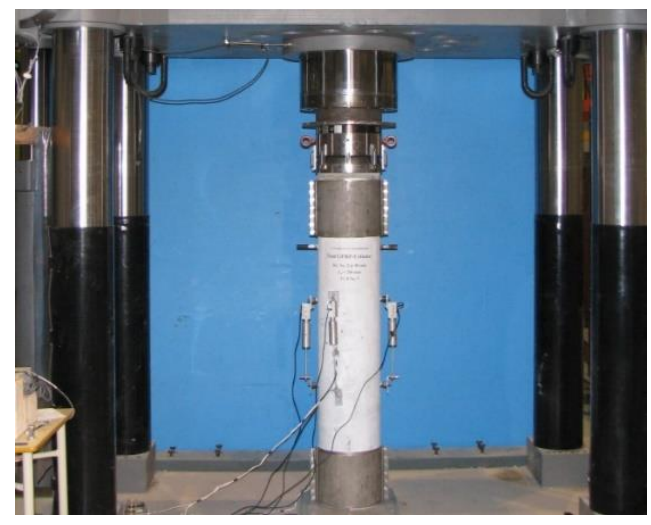

Figure 2. Test Setup

Table 2. Test matrix, specimen details, and test results

\begin{tabular}{|c|c|c|c|c|c|c|c|c|c|c|c|c|c|c|c|}
\hline \multirow{2}{*}{ Group } & \multirow{2}{*}{$\begin{array}{l}\text { Specimen } \\
\text { ID }\end{array}$} & \multicolumn{2}{|c|}{$\begin{array}{c}\text { Longitudinal } \\
\text { Reinforcement }\end{array}$} & \multicolumn{3}{|c|}{$\begin{array}{c}\text { Transverse } \\
\text { Reinforcement }\end{array}$} & \multirow{2}{*}{$\begin{array}{l}P_{\max } \\
(k N)\end{array}$} & \multirow{2}{*}{$\begin{array}{l}\mathcal{E}_{c} \\
\mu \varepsilon\end{array}$} & \multirow{2}{*}{$\begin{array}{c}\mathcal{E}_{\text {bar }} \\
\mu \varepsilon\end{array}$} & \multirow{2}{*}{$\begin{array}{l}\mathcal{E}_{s p i} \\
\mu \varepsilon\end{array}$} & \multirow[b]{2}{*}{$\mathrm{MPa}$} & \multirow{2}{*}{$\frac{f_{c c}^{\prime}}{f_{c o}^{\prime}}$} & \multirow{2}{*}{$\begin{array}{c}P_{b a r} \\
(k N \\
)\end{array}$} & \multirow{2}{*}{$\begin{array}{c}P_{b a r} \\
P_{\max } \\
\%\end{array}$} & \multirow{2}{*}{$\frac{P_{\max }-P_{b a r}}{f_{c}^{\prime} A_{c}}=$} \\
\hline & & $\begin{array}{c}\rho_{s} \\
\%\end{array}$ & $\begin{array}{c}\text { Number } \\
\text { of bars }\end{array}$ & $\begin{array}{c}\rho_{s t} \\
\%\end{array}$ & $\begin{array}{l}\text { bar } \\
\text { No. }\end{array}$ & $\begin{array}{l}\text { pitch } \\
(\mathrm{mm})\end{array}$ & & & & & & & & & \\
\hline \multirow{3}{*}{ I } & $\mathrm{P}$ & --- & --- & -- & --- & --- & 2468 & 1672 & --- & --- & --- & --- & & -- & --- \\
\hline & S2 & 1.7 & 6 No.5 & 1.6 & 3 & 40 & 3177 & 2543 & 2300 & 458 & 75.3 & 2.11 & 504 & 15 & 89.2 \\
\hline & S1 & 1.7 & 6 No.5 & 3.3 & 3 & 80 & 3141 & 2195 & 2095 & 282 & 60.2 & 1.69 & 504 & 15 & 88.0 \\
\hline \multirow{3}{*}{ II } & G1 & 2.2 & 8 No. 5 & 1.5 & 3 & 80 & 2920 & 2119 & 2120 & 268 & 61.8 & 1.74 & 215 & 7 & 90.3 \\
\hline & $\mathrm{G} 2$ & 1.1 & 4 No. 5 & 1.5 & 3 & 80 & 2826 & 2471 & 2517 & 938 & 49.8 & 1.40 & 128 & 6 & 90.1 \\
\hline & G3 & 3.2 & 12 No. 5 & 1.5 & 3 & 80 & 2998 & 2092 & 1885 & 131 & 64.9 & 1.82 & 287 & 10 & 90.5 \\
\hline \multirow{2}{*}{ III } & G4 & 2.2 & 8 No. 5 & 0.7 & 2 & 80 & 2857 & 1746 & 1338 & 383 & 49.2 & 1.38 & 136 & 5 & 90.8 \\
\hline & G5 & 2.2 & 8 No. 5 & 2.7 & 4 & 80 & 3019 & 2141 & 2376 & 44 & 64.4 & 1.81 & 241 & 8 & 92.7 \\
\hline \multirow{2}{*}{ IV } & G6 & 2.2 & 8 No. 5 & 3.0 & 3 & 40 & 2964 & 2740 & 2484 & 589 & 68.9 & 1.93 & 252 & 9 & 90.5 \\
\hline & G7 & 2.2 & 8 No. 5 & 1.0 & 3 & 120 & 2804 & 2358 & 1964 & 175 & 48.2 & 1.35 & 199 & 7 & 87.0 \\
\hline \multirow{2}{*}{ V } & G8 & 2.2 & 8 No. 5 & 1.5 & 2 & 35 & 2951 & 2159 & 2228 & 101 & 62.5 & 1.76 & 226 & 8 & 91.0 \\
\hline & G9 & 2.2 & 8 No. 5 & 1.5 & 4 & 145 & 2865 & 2311 & 2160 & 120 & 46.0 & 1.29 & 219 & 8 & 88.3 \\
\hline
\end{tabular}

Note: $\varepsilon_{c}, \varepsilon_{\text {bar }}$, and $\varepsilon_{\text {spiral }}$ were measured at $P_{\max }$

\section{EXPERIMENTAL RESULTS AND DISCUSSION}

Table 2 summarizes the experimental results of the tested specimens in terms of peak load $\left(P_{\max }\right)$, corresponding concrete strain $\left(\varepsilon_{c}\right)$, and the corresponding measured average axial strain in the longitudinal and spiral reinforcements $\left(\varepsilon_{b a r}\right.$ and $\left.\varepsilon_{\text {spiral }}\right)$, respectively. Figure 3 depicts the cracking appearance of all the specimens after failure. The plain-concrete column failed suddenly after reaching its peak load level $(2,468$ $\mathrm{kN}$ ), at a strain equal to $1,672 \mu \varepsilon$. These values are significantly less than what was observed for the GFRP and steel RC columns, (see Table 2). Moreover, this specimen's tested concrete strength (36 MPa) was 84\% of the concentric strength measured on standard cylinders. The GFRP and steel RC columns showed similar initial behavior. During testing, limited vertical hairline cracks started to appear at approximately $85 \%$ to $95 \%$ of their peak loads. The maximum axial load, $P_{\max }$, sustained by each GFRP RC specimen varied between 2,804 and 3,019 $\mathrm{kN}$. The higher loads correspond to specimens that were well confined. The average maximum axial load of the two steel RC specimens was $3,159 \mathrm{kN}$, which is $8.0 \%$ higher than that of the GFRP RC specimens. At this load level, the average axial strain in the GFRP bars in the GFRP RC specimens varied between 1,885 and $2,517 \mu \varepsilon$, with an average value equal to $2,119 \mu \varepsilon$, which is generally lower than $15 \%$ of the ultimate tensile strain $(15,960 \mu \varepsilon)$. The corresponding average strain for the axial bars in the steel RC specimens was $2,150 \mu \varepsilon$, which is close to the yield strain, and contributed approximately $15 \%$ of the ultimate column capacity. Although the columns were checked for concentric loading, crack formation was not uniform on all sides. Therefore, the initial spalling often occurred on one 
side, resulting in a small eccentricity of load. The cracks soon propagated to the other sides. After that, the columns lost $10 \%$ to $20 \%$ of their maximum capacities due to the sudden spalling of the concrete cover, where the average measured axial concrete strains ranging from 2,600 to 4,000 $\mu \varepsilon$. The cover spalling was marked by the separation of large pieces of concrete. Once the cover spalled, significant microcracking in the core caused the core to dilate, activating the passive confining pressure of the spiral reinforcement. As a result, the concrete crushed or the GFRP spiral ruptured after buckling of the longitudinal bars (see Figure $3)$.

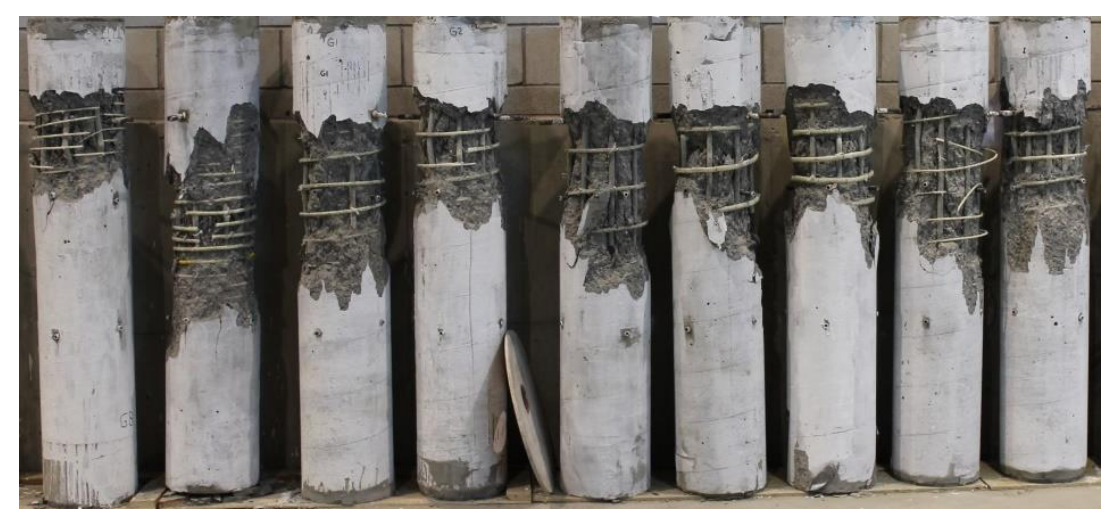

Figure 3. Overview of the failure modes of GFRP RC columns

\section{Effect of test variables on the behavior of GFRP RC columns}

In order to study the effect of each variable on the behavior of the GFRP RC columns, the load-strain response curves of the test specimens are compared in Figures 4-8. All columns initially behaved similarly and exhibited linear load-strain behavior in the ascending part up to $85 \%$ of their peak loads. The peak load and corresponding axial strain varied somewhat, depending on the effect of the test parameters on the confinement efficiency of the concrete core. Table 2 shows the strength enhancement of concrete core due to confinement, which is indicated by the ratio $f_{c c}^{\prime} / f_{c o}^{\prime}$, where $f_{c c}^{\prime}$ is the confined concrete strength and $f_{c o}^{\prime}$ is the in-place compressive strength of the unconfined concrete in the column $\left(0.85 f_{c}^{\prime}\right)$.

\section{Effect of reinforcement type}

The two GFRP RC columns (G6 and G1) were designed to have 8 longitudinal No. 5 GFRP bars based on the equivalent strength $\left(f_{y} A_{s t}=0.35 f_{f u} A_{F}\right)$ of $6 \mathrm{M} 15$ longitudinal steel bars used in the two counterpart specimens (S2 and S1), where $A_{s t}$ and $A_{F}$ are the area of steel and GFRP longitudinal reinforcement, respectively, and $f_{f u}$ and $f_{y}$ are the ultimate FRP tensile strength and steel yield strength, respectively. A reduction factor of 0.35 was chosen to account for the reduction in the compressive strength of the GFRP bars. The two GFRP RC specimens (G6 and G1) with 40 and $80 \mathrm{~mm}$ spiral spacings exhibited the same axial load-strain behavior as the steel RC counterparts (S2 and S1) (see Figure 4). Using GFRP and steel reinforcement increased the peak loads to 1.20 and 1.27 times that of the plain specimen, respectively. Table 2 indicates that the confinement efficiency provided by using GFRP longitudinal bars and spirals in the GFRP RC specimens, as measured by the strength enhancement of the concrete core $\left(f_{c c}^{\prime} / f_{c o}^{\prime}\right)$ at the maximum stress, were similar for the steel RC counterparts. The $f_{c c}^{\prime} / f_{c o}^{\prime}$ ratios in correspondence with the maximum stress for the GFRP and steel RC specimens ranged from 1.7 to 2.1. The higher ratios were observed for the well-confined specimens with high volumetric ratios (pitch of $40 \mathrm{~mm}$ ). The axial capacities of the GFRP RC columns (G6 and G1) were not significantly affected (on average, 7.0\% less) compared to their steel RC counterparts. The GFRP column (G1), however, exhibited ductile behavior, showing a lower rate of strength decay after peak than in the case of its steel counterpart (S1). The average load carried by 
the longitudinal GFRP reinforcement ranged from 5\% to $10 \%$ of the peak load $\left(P_{\max }\right)$, whereas the average load carried by the longitudinal steel reinforcement was approximately $16 \%$ of the peak load. This indicates that the GFRP bars carried less stress than the steel ones because of the lower modulus of elasticity and the concrete carried more stress than in the steel counterpart due to its reserve capacity. This result is consistent and in good agreement with the research work and experimental test results conducted on square GFRP RC columns.

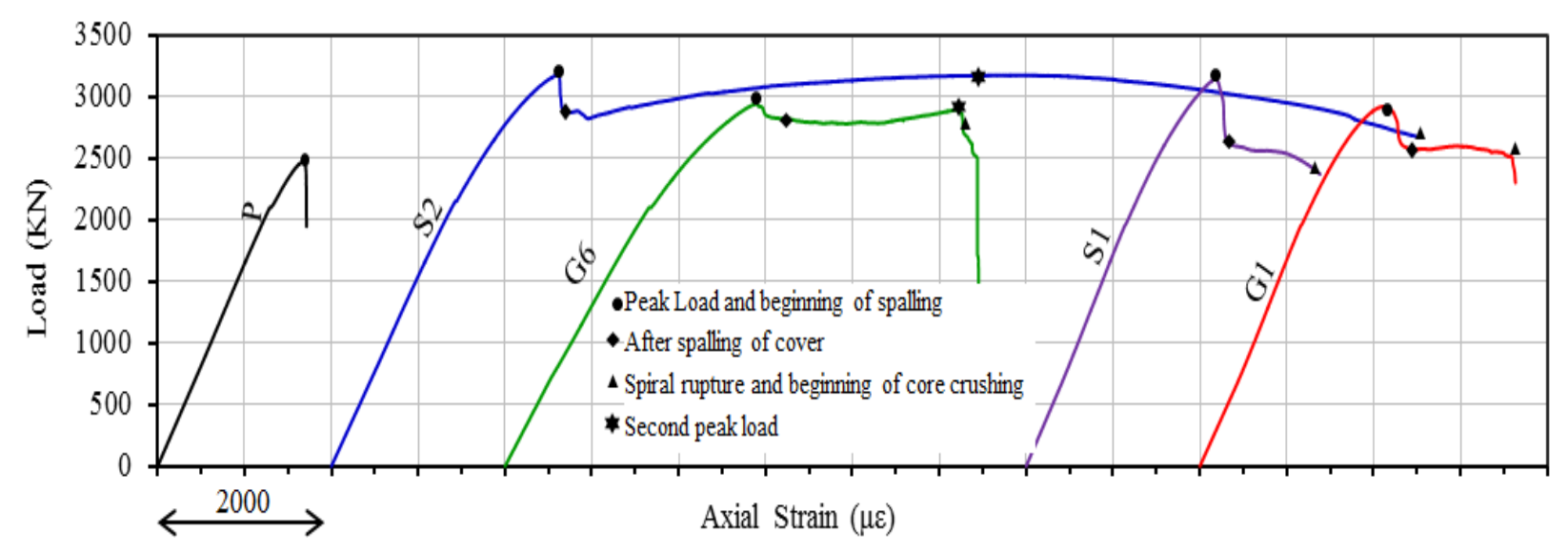

Figure 4. Effect of reinforcement type on the load-strain curves

\section{Effect of longitudinal GFRP reinforcement ratio}

Figure 5 shows the load-strain behavior of the three GFRP RC columns (G2, G1, and G3) that were designed with three longitudinal reinforcement ratios (1.1,2.2, and 3.2\%, respectively). The specimens with a low reinforcement ratio (1.1\%) failed in a brittle and explosive manner compared to the ductile behavior of the specimens with higher reinforcement ratios (2.2\% and 3.2\%). Specimens G2, G1, and G3 lost 25\%, $15 \%$, and $10 \%$ of their maximum capacity after reaching the peak load due to the sudden spalling of the concrete cover. This behavior significantly affected the ductility and confinement efficiency of the tested specimens. Increasing the reinforcement ratio enhanced the ductility and confinement efficacy. The higher ratios were obtained for specimens with higher reinforcement ratios. Moreover, increasing the longitudinal reinforcement ratio from $1.1 \%$ to $3.2 \%$ reduced the strain at peak load $\left(\varepsilon_{c}\right)$ by $20 \%$, the corresponding vertical strain reinforcement $\left(\varepsilon_{\text {bar }}\right)$ by $25 \%$, and the transverse reinforcement strain at peak load $\left(\varepsilon_{\text {spiral }}\right)$ by $86 \%$. On the other hand, Table 2 shows an enhancement in strength of $6 \%$ when the longitudinal reinforcement ratio was increased from $1.1 \%$ to $3.2 \%$.

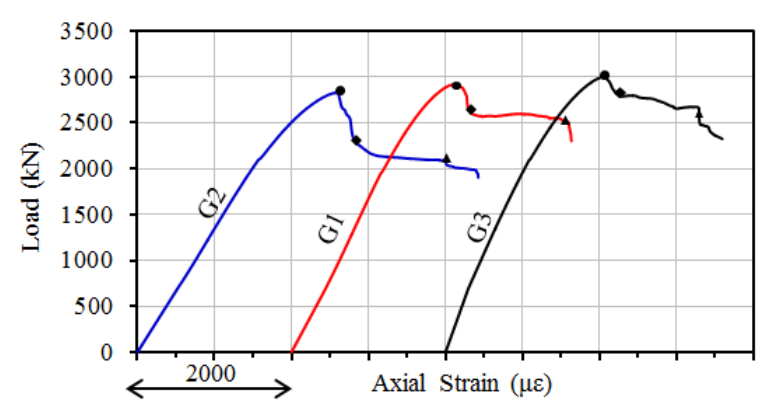

Figure 5. Effect of GFRP Reinforcement Ratio Effect of GFRP spiral spacing

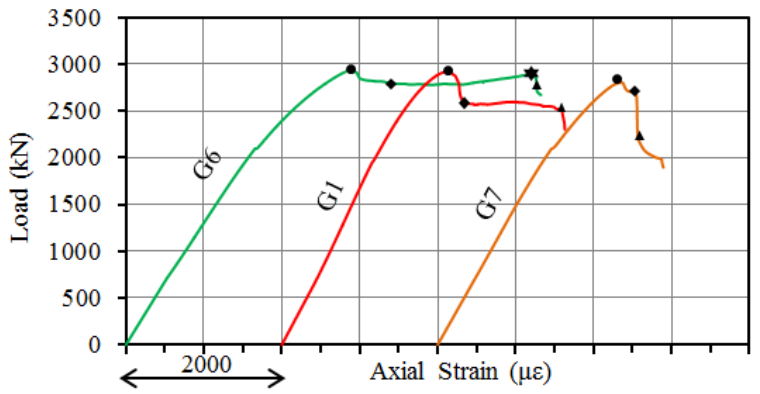

Figure 6. Effect of GFRP spiral spacing 
The importance of the amount of spiral confining reinforcement or volumetric ratio as a function of spiral spacing on the behavior of confined concrete is generally acknowledged. An increase in the volumetric ratio or closer spiral spacing may directly translate into a proportional increase in lateral confining pressure with an enhancement in confinement efficacy (Sharma et al. 2005; Cusson and Paultre 1994; Sheikh and Toklcuc 1983). Moreover, the spacing of spiral reinforcement is an important parameter affecting the stability of longitudinal bars against local buckling at maximum stress. This behavior is demonstrated in the load-strain curves of the three GFRP RC columns (G6, G1, and G7), which were designed with three different spacings of 40, 80, and $120 \mathrm{~mm}$, respectively (see Figure 6). The volumetric ratio was increased while decreasing spiral spacing while using the same GFRP spiral diameter (No. 3). Table 2 shows the increase in the spiral strain at the peak load from 175 to $589 \mu \varepsilon$ with increasing volumetric ratio, indicating the enhancement in lateral pressure. As expected, the specimens with the higher volumetric ratios or closer GFRP spiral spacings $(40$ and $80 \mathrm{~mm})$ showed ductile behavior. The specimen with the largest spacing $(120 \mathrm{~mm})$ showed brittle behavior, presenting a faster rate of strength decay after the peak. In addition, the spiral spacing controlled the buckling of the longitudinal bars. The test results indicated that, among all the tested GFRP $\mathrm{RC}$ specimens in this study, the well-confined specimens (40 $\mathrm{mm}$ spiral spacing) reached a second peak load after full cover spalling. An increase of $6.0 \%$ in strength, $29 \%$ bar-strength contribution, and $43 \%$ in the confinement efficiency $\left(f_{c c}^{\prime} / f_{c o}^{\prime}\right)$ was obtained as the volumetric ratio of spirals increased from $1.0 \%$ to $3.0 \%$. Figure 6 shows the effect of spiral spacing on the peak and post-peak cracking behavior of tested specimens in terms of axial strain versus lateral strain. The initial slope of all the curves indicated the perfectly elastic condition. At the strain equivalent to the unconfined concrete strain, the curves deviate from this line with vertical slope, and reach their maximum as the load approaches its peak value. This point corresponds to the onset of uncontrolled crack growth leading to failure. In case of the GFRP RC column with the larger spiral spacing (specimen G7), the post-peak branch was limited in extent and rapidly extended vertically into failure. In the case of the GFRP RC columns with closer spiral spacing (specimens G6 and G1), the post-peak branch showed larger development and more stable crack progression. This can be attributed to the fact that the close spiral spacing constrained the cracked concrete core laterally and delayed unstable crack propagation.

\section{Effect of GFRP spiral size}

Figure 7 shows the load-strain behavior of the three GFRP RC columns (G4, G1, and G5) that were prepared with three different spiral diameters (No. $6.4 \mathrm{~mm}$, No. $9.5 \mathrm{~mm}$, and No. $12.7 \mathrm{~mm}$, respectively) at constant spacing $(80 \mathrm{~mm})$. The corresponding volumetric ratios of GFRP spirals were $0.7,1.5$, and $2.7 \%$, respectively. The test results indicated that the GFRP RC column failed in a brittle and explosive manner when confined with less than $1.5 \%$ volumetric ratio of GFRP spiral reinforcement. The figure indicated that specimen with small spiral diameter (No. $6.4 \mathrm{~mm}$ ) and $0.7 \%$ volumetric ratio showed brittle behavior, presenting a faster rate of strength decay after the peak. In general, both the strength and ductility of confined core concrete increased with increasing volumetric ratio, whereas the $f_{c c}^{\prime} / f_{c o}^{\prime}$ ratio from 1.38 to 1.81. The higher ratios were obtained with specimens with higher volumetric ratios. This clearly indicates that when the concrete cover has completely spalled off, the maximum axial strength of the confined section can be significantly improved by lateral confinement. On the other hand, an increase of $5.7 \%$ in the maximum axial load and 60\% in contribution of longitudinal GFRP bars in the axial capacity were observed for GFRP RC columns as the volumetric ratio increased from $0.7 \%$ to $2.7 \%$. The significant improvement in the contribution of longitudinal GFRP bars was attributed to the fact that the GFRP spirals at the higher volumetric ratio $(2.7 \%)$ and closer spacing $(80 \mathrm{~mm})$ controlled the buckling of the longitudinal bars at the maximum stress level. In conclusion, the amount of GFRP spiral reinforcement had a much greater effect on confinement efficiency and ductility than on strength capacity. 


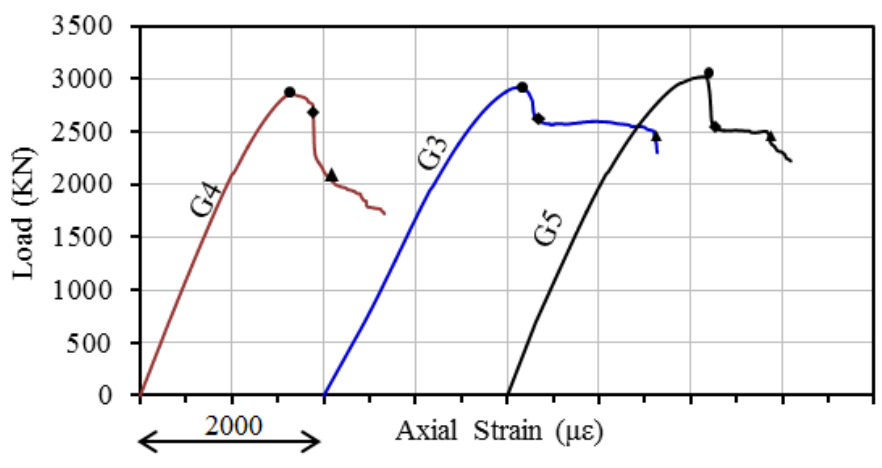

Figure 7. Effect of GFRP spiral size

\section{Effect of GFRP spiral size/spacing configuration}

In order to study the influence of the size and spacing of GFRP spirals on the behavior of GFRP RC columns, three specimens were prepared using three different spiral diameters (No. $6.4 \mathrm{~mm}$, No. $9.5 \mathrm{~mm}$, and No. $12.7 \mathrm{~mm})$ and three different spacings $(35,80$, and $145 \mathrm{~mm})$, respectively. The size and spacing of the GFRP spiral were chosen to maintain a constant volumetric ratio $(1.5 \%)$ for the three GFRP RC specimens (G8, G1, and G9). Figure 8 shows the load-strain behavior of these three GFRP RC columns. In general, the test results indicated that the GFRP RC columns with closer spacing behaved much better than those with larger spiral spacing. The GFRP RC columns with larger spacing $(145 \mathrm{~mm})$ and diameter 12.7 $\mathrm{mm}$ failed in a brittle and explosive manner immediately upon reaching peak strength. The specimen lost $37 \%$ of its maximum capacities after reaching the peak load due to the sudden spalling of the concrete cover. The GFRP specimens with closer spacing and smaller diameters (G8 and G1) showed ductile behavior in the post-peak stage, causing the column to fail in a more gradual manner than the larger GFRP spirals set at larger spacing (G9). It was also found that the smaller spirals at closer spacing offered sufficient restraint against buckling of the longitudinal GFRP bars up to the concrete's compression failure, with negligible influence on peak load. In contrast, $36 \%$ increase in the strength of the concrete core as measured by $f_{c c}^{\prime} / f_{c o}^{\prime}$ ratio, and $2 \%$ increase in the maximum load $\left(P_{\max }\right)$ were observed for columns reinforced with No. $9.5 \mathrm{~mm}$ GFRP spirals with spaced at $80 \mathrm{~mm}$ as compared to instead No. $12.7 \mathrm{~mm}$ spirals spaced at 145 $\mathrm{mm}$. Similarly, a 35\% increase in the strength of the concrete core, and 3\% increase in the maximum load $\left(P_{\max }\right)$ were observed for columns reinforced with No. $6.4 \mathrm{~mm}$ GFRP spirals spaced at $35 \mathrm{~mm}$ in comparison to No. $12.7 \mathrm{~mm}$ spirals spaced at $145 \mathrm{~mm}$. In conclusion, the ductility and confinement efficiency of the concrete core can be improved by using smaller diameter GFRP spirals with closer spacing than by using larger diameter spirals with larger spacing.

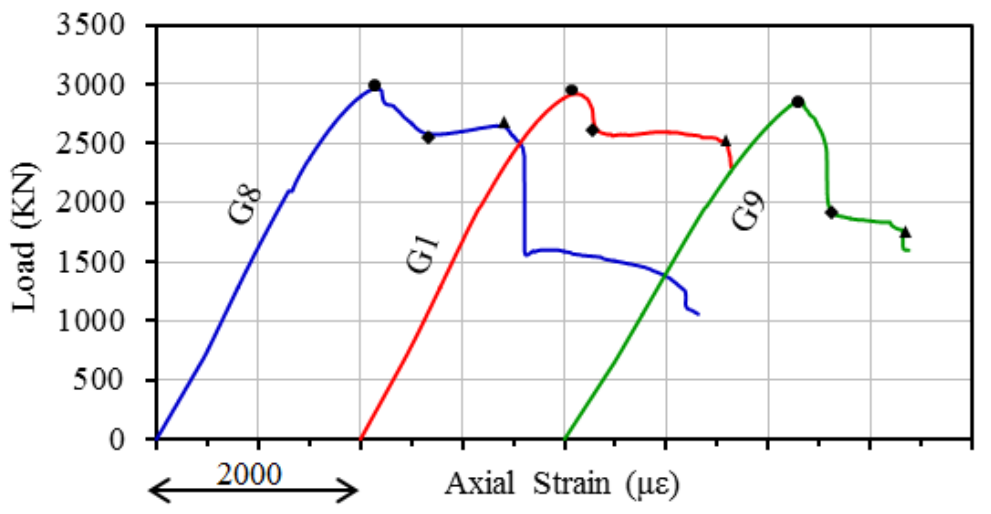

Figure 8. Effect of GFRP spiral size/spacing configuration 


\section{CONCLUSION}

Based on the experimental test results and analysis presented in this paper, the following conclusions can be drawn:

1. The GFRP and steel RC columns behaved in a similar manner and exhibited linear load-strain behavior in the ascending part up to $85 \%$ of their peak loads. The axial capacities of the GFRP RC columns were on average $7.0 \%$ lower than their steel RC counterparts.

2. The test observations indicated that failure of the GFRP RC columns with large spiral spacing or with small volumetric ratio $(0.7 \%)$ was controlled by longitudinal bar buckling. Conversely, failure of the well-confined GFRP RC columns was attributed to the crushing of the concrete core and rupture of the GFRP spirals.

3. The amount and distribution of longitudinal GFRP reinforcement significantly affected column ductility, with a slight strength gain. The average load carried by the longitudinal GFRP bars in the GFRP RC columns ranged between $5 \%$ and $10 \%$ of the maximum load.

4. GFRP spiral spacing had a much greater impact on confinement efficiency and ductility than on strength capacity. Smaller spirals with closer spacing offered sufficient restraint against buckling of the longitudinal GFRP bars.

5. The ductility and confinement efficiency of the concrete core can be improved by using smaller GFRP spirals with closer spacing than by using larger diameter spirals with larger spacing.

6. The GFRP specimens with closer spacing and smaller diameters showed ductile behavior in the postpeak stage, causing the column to fail in a more gradual manner than those with larger GFRP spirals at larger spacing. The GFRP RC columns failed in a brittle and explosive manner when confined with less than a $1.5 \%$ volumetric ratio, or with spiral spacing over $80 \mathrm{~mm}$ even at volumetric ratios higher than $1.5 \%$.

\section{REFERENCES}

American Concrete Institute (ACI) Committee 440. (2006). Guide for the design and construction of concrete reinforced with FRP bars, ACI 440.1R-06, Farmington Hills, Mich.

Canadian Standards Association (CSA). (2012). Design and construction of building components with fiber reinforced polymers, CAN/CSAS806-12, Rexdale, Toronto.

Canadian Standards Association (CSA). (2006-Edition 2010). Canadian highway bridge design code(Section 16), CAN/CSA-S6-06, Rexdale, Toronto.

Cusson, D., and Paultre, P. (1994)."High-strength concrete columns confined by rectangular ties.” Journal of Structural Engineering, ASCE, 120(3), 783-804.

De Luca, A., Matta, F., and Nanni, A. (2010). "Behavior of full-scale glass fiber-reinforced polymer reinforced concrete columns under axial load.” ACI Structural Journal, 107 (5), 589-596.

ISIS Canada (2009). "Intelligent Sensing for Innovative Structures" http://www.isiscanada.com

Kobayashi, K., and Fujisaki, T. (1995). "Compressive behavior of FRP reinforcement in non-prestressed concrete members." Proceedings of the $2^{\text {nd }}$ International RILEM Symposium on Non-Metallic (FRP) Reinforcement for Concrete Structures, Ghent, Belgium, 267-274.

Lotfy, E. M. (2010). "Behavior of Reinforced Concrete Short Columns with Fiber Reinforced Polymers Bars." International Journal of Civil and Structural Engineering, 1 (3), 545-557.

Pultrall Inc, (2012). “Composite Reinforcing Rods Technical Data Sheet." Thetford Mines, Canada, www.pultrall.com. 
Sharma, U. K., Bhargava, P., and Kaushik, S.K. (2005). "Behavior of confined high strength concrete columns under axial compression." Journal of Advanced Concrete Technology, 3 (2), 267-281.

Sheikh, S. A. and Toklcuc, M. T. (1993). "Reinforced concrete columns confined by circular spirals and hoops." ACI Structural Journal, 90(5), 542-553.

Tobbi, H., Farghaly A. S., and Benmokrane B. (2012). "Concrete columns reinforced longitudinally and transversally with glass fiber-reinforced polymers bars.” ACI Structural Journal, 109 (4), 1-8. 